\title{
Formação Docente e Sustentabilidade. Um Estudo sobre Ambientalização Curricular no Curso de Pedagogia da Universidade Estadual do Oeste do Paraná
}

\author{
Knowledge Base for Teaching and Sustainability. A Study about \\ Curricular Environmentalization on Pedagogy Course of State \\ University of West Paraná
}

\author{
Talita Rechia Vasconcellos da Rosa* \\ Vilmar Malacarne \\ Universidade Estadual do Oeste
}

\begin{abstract}
Este trabalho apresenta os resultados da análise documental do curso de Pedagogia da Universidade Estadual do Oeste (Unioeste), campus de Cascavel, Paraná, Brasil. O objetivo desse artigo é expor como está o processo de ambientalização curricular deste curso a partir da análise dos ementários das disciplinas, utilizando como parâmetros os indicadores da Rede de Ambientalização Curricular do Ensino Superior (ACES), as Diretrizes Curriculares Nacionais para a Educação Ambiental (DCNEA) e a Política Nacional de Educação Ambiental (PNEA), como base para a apreensão de conteúdos de sustentabilidade. A análise documental realizou-se por meio de técnicas do método Análise de Conteúdo de Bardin (2011) cujos resultados indicaram que a inserção de conteúdos de sustentabilidade nas ementas das disciplinas, do curso de Pedagogia, apresentam princípios mínimos da Rede ACES e DCNEA, evidenciando uma Educação Ambiental frágil e incipiente na formação dos pedagogos. Os dados possibilitaram verificar a premente necessidade de alteração nos currículos para a formação destes profissionais para que se configure um percurso formativo em sintonia com as necessidades de educação de novas gerações comprometidas com um desenvolvimento sustentável no Brasil.
\end{abstract}

Palavras-chave: Formação docente, Currículo, Educação ambiental, Sustentabilidade.

This work presents the results of the document analysis of the Pedagogy course of State University of West, campus of Cascavel, Paraná, Brazil. The purpose of this article is to show how is the curriculum environmentalization process of this course through the analysis of the disciplines curriculum, using as parameters the Curriculum Environmentalization of Higher Education (ACES) Network indicators, the National Curriculum Guidelines for Environmental Education (DCNEA) and the National Environmental Education Policy (PNEA) as a basis for the seizure of sustainability content. The document analysis was performed through the techniques of the Bardin (2011) Content Analysis method in which the results indicated that the insertion of sustainability content on the curriculum of disciplines, from Pedagogy course, presents minimum principles of ACES Network and DCNEA, showing a fragile and incipient Environmental Education in teacher training. The data enabled to verify the pressing need to change the curricula for these professionals training to set up a formative path in line with education needs of the new generations committed to the sustainable development in Brazil.

Keywords: Teacher training, Curriculum, Environmental education, Sustainability.

*Contacto: tali_rechia@hotmail.com

ISSN: 1696-4713

www.rinace.net/reice/

revistas.uam.es/reice
Recibido: $\quad 15$ de agosto 2015

$1^{\text {a }}$ Evaluación: 1 de octubre 2015

$2^{\text {a }}$ Evaluación: 9 de febrero 2015

Aceptado: 1 de abril 2013 


\section{Introdução}

O presente trabalho apresenta uma pesquisa documental que teve por objetivo apreender a presença de conteúdos de sustentabilidade no ementário de disciplinas do curso de Pedagogia da Universidade Estadual do Oeste do Paraná (Unioeste) do campus de Cascavel, Paraná, Brasil. O escopo foi o de identificar se há um processo de ambientalização curricular neste curso, considerando a problemática da frágil formação em Educação Ambiental (EA) nas instituições de Ensino Superior no Brasil, já constatada em pesquisas anteriores (Guerra, 2013; Zuin e Freitas, 2007).

Para tanto, realizou-se primeiramente estudos bibliográficos sobre a temática e suas diferentes vertentes com o intuito de apreender os conceitos e definições de sustentabilidade. A partir desta pesquisa inicial foi possível identificar as legislações e organizações em torno da sustentabilidade, o que nos levou à pesquisa documental.

Apresentam-se, neste artigo, a análise das ementas das disciplinas do curso de Pedagogia que foram utilizadas como objeto de pesquisa, tendo como base os indicadores da Rede de Ambientalização Curricular para o Ensino Superior (ACES), bem como as Diretrizes Curriculares Nacionais para Educação Ambiental (DCNEA) e a Política Nacional de Educação Ambiental (PNEA). Para a utilização destes documentos como instrumentos de análise, fez-se necessário estabelecer categorias, utilizando-se a técnica de Análise de Conteúdo de Bardin (2011) para a extração dos conteúdos dos mesmos.

Constatou-se que a legislação educacional brasileira vem demonstrando compromisso com os problemas ambientais atuais e ameaças ao futuro da humanidade, como, principalmente, as discussões em torno do aquecimento global, que trazem discussões mundiais sobre a inserção da temática do desenvolvimento sustentável nas diversas áreas de conhecimento no ensino superior, em especial na formação de professores.

As mudanças climáticas estão no topo das discussões referentes às questões ambientais, visto que o aumento gradual da temperatura mundial pode causar impactos ambientais como, por exemplo, o derretimento das geleiras, que causaria o alagamento de algumas cidades litorâneas, o aumento das secas nas regiões mais quentes, o aumento de tufões e furacões, a morte ou até a extinção de alguns animais de ambientes árticos (Gore, 2006).

Tratar desse assunto nos diversos espaços sociais, especialmente nas instituições educacionais, pode contribuir para a conscientização das consequências de nosso modo de produção e consumo atual. Um dos caminhos para formar cidadãos responsáveis por uma sociedade comprometida com um bem comum e com as próximas gerações é a Educação Ambiental desde os anos iniciais, ressaltando-se que os pedagogos são habilitados para atuar neste nível de ensino.

Constitui-se um avanço na legislação educacional brasileira para o enfrentamento da problemática, em questão, a criação das Diretrizes Curriculares Nacionais para a Educação Ambiental, assim como a Política Nacional para a Educação Ambiental, as quais orientam que as instituições de ensino tornem-se espaços educadores sustentáveis. No entanto, em que pese as exigências da legislação brasileira, pergunta-se: $O$ curso de Pedagogia da Unioeste está em um processo de ambientalização curricular?

Nesta analise documental, foi constatado que este curso está em um processo de ambientalização muito incipiente e frágil com uma perspectiva de formação voltada para as especialidades de pedagogo não docente, que atua como coordenador pedagógico e, 
pedagogo docente, que atua na Educação Infantil e nos Anos Iniciais do Ensino Fundamental sem abarcar, no entanto, questões que perpassam todas as disciplinas, como é o caso da sustentabilidade.

\section{Fundamentação teórica}

Muitos economistas defendem que se deve priorizar o crescimento econômico em curso, principalmente nos países em desenvolvimento. Diferentemente, alguns autores (Al Gore, 2006; Boff, 2014; Sachs, 2009a, 2009b; Veiga, 2010a, 2010b), se contrapondo a essa lógica, afirmam que a sociedade atual caminha para a extinção da espécie humana, uma vez que, desde a Revolução Industrial (1760), houve um forte crescimento econômico e o estímulo das sociedades ao consumo.

Não há como evitar o consumo devido às necessidades de sobrevivência e/ou bem-estar de nosso modo de vida atual. No entanto, há estudiosos (Al Gore, 2006; Boff, 2014; Sachs, 2009a, 2009b; Veiga, 2010a, 2010b) que consideram possível conter o excessivo consumo conciliando o crescimento econômico com o desenvolvimento sustentável. $\mathrm{O}$ enfrentamento da problemática ambiental e a mudança de comportamento relacionado à produção e consumo da sociedade, pode garantir às gerações futuras o suprimento de suas necessidades por um longo período.

A Educação formal tem o potencial de propalar a temática sustentabilidade, visto que alcança a maior parte da população mundial. William Nordhaus (Veiga, 2010a), apontado como o pesquisador mais antigo da economia do aquecimento global, afirma que se deve começar reduzindo moderadamente as emissões dos gases de efeito estufa, simultaneamente investindo-se na educação, ciência, tecnologia e inovação, para que, quando a sociedade atingir um determinado patamar de qualidade de vida, se possa intensificar a redução das emissões.

A preocupação com a inserção de temáticas relacionadas à Sustentabilidade nas universidades é relativamente recente. De acordo com Guerra (2013), a Rede ACES foi desenvolvida nos anos 2000, financiada pela Comissão Europeia, por meio de um projeto intercultural/interdisciplinar que envolveu 11 universidades provenientes de sete países (Alemanha, Argentina, Brasil, Cuba, Espanha, Itália e Portugal), cujo objetivo seria o de investigar o grau de ambientalização curricular no ensino superior para a formação de futuros profissionais e gestores comprometidos com a busca permanente das melhores relações possíveis entre a sociedade e a natureza, atendendo aos valores da justiça, da solidariedade e da equidade, aplicando os princípios éticos reconhecidos universalmente e o respeito às diversidades.

A forte demanda por uma sociedade sustentável traz para os currículos de formação docente a premente necessidade de contemplar conteúdos relacionados à sustentabilidade. Entretanto, apesar das demandas sociais e das determinações legais, outras pesquisas também indicam uma frágil formação ambiental em instituições de ensino superior como, por exemplo, as pesquisas desenvolvidas por Zuin e outros (2009).

Embora o consumo supérfluo predomine na sociedade contemporânea, a necessidade de promover ações para o desenvolvimento da consciência ambiental já é um assunto emergente desde o século XIX. 
No entanto, o discurso da sustentabilidade manifestou-se, pela primeira vez, somente em 1987, no relatório da Comissão de Brundtland, denominado Our common future (Nosso futuro comum, tradução livre), presidida por Gro Harlem Brundtlandt e Mansour Khalid, a Comissão foi resultado do trabalho da Comissão Mundial sobre o Meio Ambiente e Desenvolvimento, da ONU, criada em 1983, após uma avaliação dos 10 anos da Conferência de Estocolmo. Neste discurso o desenvolvimento sustentável é definido como o "... desenvolvimento que satisfaz as necessidades do presente sem comprometer a capacidade de gerações futuras satisfazerem suas próprias necessidades" (Moraes, 2011, p. 17).

Nessa perspectiva, ressalta-se que os recursos naturais são finitos e que há uma grande necessidade de redução do uso de matérias-primas, do aumento da reutilização e da reciclagem e o planejamento do futuro econômico, social e cultural da sociedade. Eis aí o grande desafio que permeia todas as áreas do conhecimento: conciliar o desenvolvimento econômico e social com o impacto ambiental. As enormes transformações sociais e econômicas do homem moderno evidenciam o quanto esta modernidade subordinou a natureza ao desenvolvimento das ciências, da tecnologia e às ideias de progresso (Vilela, 2011).

Na década de 1970, o estilo de vida consumista nos faz presenciar as primeiras catástrofes mundiais naturais relacionadas a este progresso, apontando também para as primeiras evidências da falta de recursos naturais, reflexo do uso desmedido de matérias-primas (Moraes, 2011). Essas transformações foram evidenciadas em meados do século XX, principalmente no Grupo dos Sete (Estados Unidos, Japão, Alemanha, Reino Unido, França, Itália e o Canadá), demandando um crescente consumo de energia, de comunicações e de transporte, principais itens da infraestrutura econômica, aliado as necessidades de saúde, educação, saneamento básico, trabalho e alimentação, causando enormes impactos ambientais em áreas urbanas e rurais. Tal fato também ocorreu com maior evidência, a partir dos anos 1980, nos países em desenvolvimento, particularmente nos BRICS (Brasil, Rússia, Índia, China e África do Sul). Com as novas necessidades surgidas, em função do aumento populacional e estímulos exagerados de consumo, advindos inicialmente e principalmente do $\mathrm{G} 7$, a fim de manter suas economias, transferiuse a produção de bens de consumo para os países em desenvolvimento, causando-lhes enormes impactos ambientais (Mészaros, 2003).

Estas transferências passaram a serem discutidas apenas no final do século XX, com a criação de regras para minimizarem as principais agressões ao meio ambiente, quais sejam: o desmatamento; a expansão agropecuária; a urbanização; e a poluição. O discurso de um desenvolvimento sustentável chegou ao século XXI pela iminente necessidade de acompanhar os avanços da ciência e da tecnologia conciliando com as necessidades culturais atuais e a convivência harmônica com o meio ambiente.

Segundo Sachs (2009a), na Conferência de Estocolmo, primeira Conferência das Nações Unidas sobre o Meio Ambiente, realizada em junho de 1972, em Estocolmo, capital da Suécia, o diretor do Programa das Nações Unidas para o Meio Ambiente (PNUMA), Maurice Strong, lançou a palavra "ecodesenvolvimento", que posteriormente veio a ser chamado de desenvolvimento sustentável, antes mesmo de se ter um conteúdo sobre este assunto: "primeiro houve o vocábulo, e depois começou-se a escavar o conteúdo. Portanto, trabalharíamos por vários anos no aperfeiçoamento do conceito de ecodesenvolvimento, que nesse meio-tempo se transformara em "desenvolvimento sustentável” (p. 234). 
Apesar de, por suas definições, a EA e a Sustentabilidade serem compreendidas como temáticas semelhantes, deve-se considerar suas distinções. A educação para o desenvolvimento sustentável não deve ser equiparada à EA. Segundo Capra (2006), para tornar possível uma sociedade sustentável, deve-se seguir o modelo dos princípios organizacionais dos ecossistemas da natureza, ou seja, um sistema não-linear, neste caso, um sistema de rede.

Entende-se por este sistema de rede, as infindas relações de dependência na evolução de todos os organismos, ou seja, essas tramas de relações podem compreender, por vezes, retrocessos para avanço. Sob esta perspectiva não se vincula a ideia do progresso positivista isolado, ou de verdades absolutas, mas históricas, do movimento de um processo interativo do todo às partes e das partes ao todo.

Atualmente, ainda de acordo com Capra (2006), para compreender a ecologia, é preciso atentar-se aos conceitos da teoria dos sistemas vivos que pode ser segmentado por três eixos: em primeiro lugar, todo organismo vivo, por mais minúsculo que seja, refere-se a um sistema vivo; segundo, cada parte do sistema vivo é, também, um sistema vivo; por último, as comunidades de organismos (ecossistemas e sistemas sociais humanos) também são sistemas vivos.

Pensar no modelo linear significa pensar na ideia de que o progresso é sempre mais do que aquilo que já temos. Entretanto, o controle das variáveis dos sistemas vivos se faz por um modelo totalmente não-linear, pois seguem propriedades individuais e essenciais que interagem como uma teia e, quando o organismo vivo funciona, maximizá-lo pode romper com o equilíbrio (Capra, 2006). A aplicação de sistemas de rede aos conceitos dos sistemas vivos para a criação de comunidades sustentáveis se configura no que o autor chama de princípios da sustentabilidade.

Para Capra (2006) ao identificar os processos e padrões pelos quais a natureza sustenta a vida, abre-se a possibilidade de compreender a sustentabilidade em um sentido mais amplo, como um sistema de rede, estruturado por propriedades individuais, algumas essenciais. Entende-se, portanto, a sustentabilidade como uma comunidade de organismos e a Educação Ambiental como parte deste organismo, como uma das propriedades essenciais de um sistema sustentável.

A EA, portanto, enfatiza a relação dos homens com o ambiente natural. Nesse raciocínio, o desenvolvimento sustentável engloba a EA, colocando-a em um contexto mais amplo dos fatores socioculturais e questões sociopolíticas de igualdade, pobreza, democracia e qualidade de vida. A perspectiva de desenvolvimento, envolvendo mudança social e evolução das condições, é também central para qualquer análise do desenvolvimento sustentável (Unesco, 2005).

Atualmente a EA, segundo Guimarães (2013), tem sido vista como uma das principais formas de lidar com a grave crise socioambiental que estamos sofrendo, indicando o esgotamento do modelo de desenvolvimento do modo de produção e consumo capitalista. A EA chega, portanto, para contribuir efetivamente para uma transformação socioambiental e os pedagogos podem trabalhar como agentes de mudança dessa realidade, ensinando sobre novas formas de interagir, produzir e consumir.

Para Fernandes (2013) o colossal obstáculo a ultrapassar é de um padrão insustentável para um padrão de sustentabilidade. Este autor considera que os conhecimentos produzidos em torno desta temática apontam para uma pequena relevância, por parte dos 
cidadãos brasileiros, da gestão organizacional e governamental do País e do conjunto de políticas. Muito embora, a temática da sustentabilidade, por sua característica transversal, possibilite o trânsito em todas as áreas de conhecimento.

É importante ressaltar que as Diretrizes Curriculares Nacionais para a Educação Ambiental, aprovadas pelo Conselho Nacional de Educação (CNE, 2012), referendam princípios da Constituição Federal (CF) e da Lei 9.795 de abril de 1999 que institui a Política Nacional de Educação Ambiental que recomendam às instituições de ensino promover:

... trabalho de comissões, grupos ou outras formas de atuação coletiva favoráveis à promoção de educação entre pares, para participação no planejamento, execução, avaliação e gestão de projetos de intervenção e ações de sustentabilidade socioambiental na instituição educacional e na comunidade, com foco na prevenção de riscos, na proteção e preservação do meio ambiente e da saúde humana, e na construção de sociedades sustentáveis. (Brasil., 2012, p. 6)

As Diretrizes Curriculares Nacionais para a Educação Ambiental também instituem que:

\begin{abstract}
Os sistemas de ensino devem promover as condições para que as instituições educacionais constituam-se em espaços educadores sustentáveis, com a intencionalidade de educar para a sustentabilidade socioambiental de suas comunidades, integrando currículos, gestão e edificações em relação equilibrada com o meio ambiente, tornando-se referência para seu território. (Brasil., 2012, p. 7)
\end{abstract}

De acordo com Zuin y Freitas (2007) a Rede ACES tem como objetivo avançar nos processos de intervenção nas práticas formativas com a finalidade de introduzir mudanças no currículo de modo a estimular que futuros profissionais exerçam suas atividades na ótica da necessidade de mudanças em relação aos aspectos ambientais. Segundo as autoras, a intervenção em uma disciplina para o processo de ambientalização é a área mais limitada que se pode atingir, tendo a possibilidade de expansão em toda grade curricular de um curso se for abordada de maneira transversal.

Capra (2006) esclarece, a partir de uma visão holística, o que são os sistemas vivos em sua totalidade e nos incita a compreender e ensinar para as novas gerações os princípios da ecologia e da vida. Afirma que “... cabe a nós aprender estes princípios e criar sistemas de educação pelos quais as gerações futuras poderão aprender os princípios e aprender a planejar sociedades que os respeitem e aperfeiçoem" (p. 57).

Nesta perspectiva, para que as instituições educacionais sejam espaços educadores sustentáveis, é mister que seja dada a devida importância para a formação inicial e continuada dos professores no sentido de que estes profissionais possuam conhecimentos científicos e, assim, competências para proporcionar aos seus alunos condições de compreender o ser humano e o meio em que vive: “... a Educação tem, como uma de suas finalidades, a preparação para o exercício da cidadania” (Brasil, 2012, p. 1).

Nas Diretrizes Curriculares Nacionais para a Educação Ambiental (Brasil, 2012), consta ainda que:

Em conformidade com a Lei $n^{\circ}$ 9.795, de 1999, reafirma-se que a Educação Ambiental é componente integrante, essencial e permanente da Educação Nacional, devendo estar presente, de forma articulada, nos níveis e modalidades da Educação Básica e da Educação Superior, para isso devendo as instituições de ensino promovê-la integradamente nos seus projetos institucionais e pedagógicos. (p. 3)

Na prática pedagógica e na vida pessoal, quanto mais clareza o docente tiver sobre o desenvolvimento sustentável, mais ele poderá contribuir para mudanças de atitudes em relação à interação do homem na natureza. 
Embora, ainda, haja pouca consciência da inter-relação entre todas as atividades humanas no meio ambiente, a materialização da temática da sustentabilidade nas Diretrizes Curriculares Nacionais para a EA é resultado de intensos debates sobre o desenvolvimento sustentável e o papel das sociedades contemporâneas na transformação de atitudes em relação ao meio ambiente (Sachs, 2009).

Em que pese este contexto, é de suma importância licenciar pedagogos, que formarão as novas gerações, implicados com uma sociedade sustentável: temos aí mais um desafio colocado para a formação de professores.

Diante da problemática das universidades se constituírem em espaços educadores sustentáveis perguntamos: Quais são os princípios de Sustentabilidade presentes nas determinações legais brasileiras? O curso de Pedagogia da Unioeste, campus de Cascavel, tem abordado a temática da Sustentabilidade? Seu currículo está em sintonia com os princípios de Sustentabilidade?

\section{Método}

A Universidade Estadual do Oeste do Paraná possui 5 campi em Cascavel, Foz do Iguaçu, Francisco Beltrão, Marechal Cândido Rondon e Toledo, municípios localizados no oeste do Paraná, região caracterizada pela intensa atividade de agronegócios. O recorte desta pesquisa está em torno do curso de Pedagogia, situado no campus de Cascavel. Este curso foi implantado na cidade no ano de 1972 e, anualmente, oferta 80 vagas para os períodos matutino e noturno. O tempo mínimo para integralização do curso é de 4 anos com uma carga horária total de 3.252 horas-aula.

No perfil profissional deste curso, consta que o Pedagogo é o profissional da educação habilitado para a atividade docente no ensino da Educação Infantil e nos anos iniciais do Ensino Fundamental. Consta, ainda, que o Pedagogo poderá atuar numa atividade não docente, como articulador da Organização do Trabalho Pedagógico e da Gestão Escolar.

No que diz respeito à analise de dados, fez-se necessário construir as categorias para identificar o processo de ambientalização do curso analisado, utilizando-se da técnica de Análise de Conteúdo de Laurence Bardin (2011). A análise de conteúdo na pesquisa documental, segundo a autora, é uma forma alternativa de abstrair informação, com o intuito de facilitar o pesquisador ao acesso aos dados, classificados em categorias.

Para tanto, as categorias foram formuladas seguindo critérios de extração de conteúdo dos documentos da Rede ACES, DCNEA e PNEA. Constatou-se, nesta análise, que a instituição da disciplina de Educação Ambiental, por seu caráter interdisciplinar, não é obrigatória em âmbito Nacional como disciplina específica, porém deve ser discutida transversalmente entre as outras disciplinas, podendo também ser optativa.

A Rede ACES estabeleceu dez indicadores considerados fundamentais para a caracterização de cursos com um currículo ambientalizado (Junyent et al., 2003), utilizados nessa pesquisa como categorias de analise:

- Compromisso para a transformação das relações sociedade-natureza;

- Complexidade;

- Ordem disciplinar (flexibilidade e permeabilidade); 
- Contextualização local-global- local e global-local-global;

- Considerar o sujeito na construção do conhecimento;

- Consideração aos aspectos cognitivos, afetivos, éticos e estéticos das pessoas;

- Coerência e reconstrução entre teoria e prática;

- Orientação prospectiva de cenários alternativos que respeitem as gerações futuras;

- Adequação metodológica;

- Espaços de reflexão e participação democrática.

Estes dez indicadores foram criados por integrantes de onze universidades provenientes de 7 países, dentre as quais destacamos as três brasileiras: Universidade Estadual Paulista (UNESP, campus Rio Claro), Universidade Federal de São Carlos (UfSCar) e Universidade Estadual de Campinas (UNICAMP).

A partir das Diretrizes Curriculares Nacionais criou-se três categorias, os parâmetros mínimos estipulados para a EA, que podem ocorrer:

- Pela transversalidade, mediante temas relacionados com o meio ambiente e a sustentabilidade socioambiental.

- Como conteúdo dos componentes já constantes do currículo.

- Pela combinação de transversalidade e de tratamento nos componentes curriculares.

Para construção destas categorias, utilizou-se a inserção dos conhecimentos concernentes à Educação Ambiental nos currículos da Educação Básica e da Educação Superior, que podem ser encontrados em Art. 16 (Brasil., 2012, p. 5).

Por último, oito categorias foram estabelecidas. Para estas categorias, identificaram-se os princípios básicos estabelecidos para a EA na PNEA:

- O enfoque humanista, holístico, democrático e participativo;

- A concepção do meio ambiente em sua totalidade, considerando a interdependência entre o meio natural, o sócio-econômico e o cultural, sob o enfoque da sustentabilidade;

- O pluralismo de ideias e concepções pedagógicas, na perspectiva da inter, multi e transdisciplinaridade;

- A vinculação entre a ética, a educação, o trabalho e as práticas sociais;

- A garantia de continuidade e permanência do processo educativo;

- A permanente avaliação crítica do processo educativo;

- A abordagem articulada das questões ambientais locais, regionais, nacionais e globais;

- O reconhecimento e o respeito à pluralidade e à diversidade individual e cultural. 
A seguir, apresenta-se a análise do ementário de disciplinas do curso de Pedagogia da Unioeste, com vista a identificar se este curso apresenta conteúdos de sustentabilidade em seu currículo.

\section{Resultados}

Analisando o ementário das disciplinas do curso de Pedagogia, verificou-se que existe um processo de ambientalização curricular, visto que, durante os 4 anos de formação atende a 6 das 10 categorias da Rede ACES. Vale ressaltar, que a categoria "Coerência e reconstrução entre teoria e prática” foi contemplada em sua totalidade, pois nas 31 disciplinas que compõe o currículo deste curso, todas têm uma carga horária destinada à atividades práticas denominadas "Atividade Prática como Componente Curricular.

No entanto, é importante destacar, aqui, que as disciplinas cujos nomes iniciam-se com “Teoria e Prática” possuem uma distribuição desproporcional de carga horária se considerarmos os parâmetros dos documentos, como podemos observar no quadro 1:

Quadro 1. Disciplinas cujo título contém as palavras Teoria e Prática

\begin{tabular}{lcccc}
\hline \multicolumn{1}{c}{ DISCIPLINA } & ANO & TEORIA & PRÁTICA & TOTAL \\
\hline Teoria e Prática do Ensino de História e Geografia & $3^{\circ}$ & $87 \mathrm{~h}$ & $15 \mathrm{~h}$ & $102 \mathrm{~h}$ \\
Teoria e Prática de Ensino da Matemática & $3^{\circ}$ & $87 \mathrm{~h}$ & $15 \mathrm{~h}$ & $102 \mathrm{~h}$ \\
Teoria e Prática de Ensino de Língua Portuguesa & $4^{\circ}$ & $58 \mathrm{~h}$ & $10 \mathrm{~h}$ & $68 \mathrm{~h}$ \\
Teoria e Prática do Ensino de Ciências Naturais & $4^{\circ}$ & $58 \mathrm{~h}$ & $10 \mathrm{~h}$ & $68 \mathrm{~h}$ \\
\hline
\end{tabular}

Fonte: Elaborado pelos autores.

Ainda pode-se verificar que, no quadro 1, a disciplina "Teoria e Prática do Ensino das Ciências Naturais”, possui uma carga horária total de 68 horas, que é a mínima das disciplinas do PPP e, somente, no último ano da formação dos futuros professores. Entretanto, a ementa da disciplina prevê o:

$$
\begin{aligned}
& \text {... estudo das relações entre homem e natureza mediadas pelo trabalho como origem da ciência, } \\
& \text { da tecnologia e da sociedade. As concepções do Ensino de Ciências Naturais, suas implicações } \\
& \text { curriculares e pedagógicas: objetivos, conteúdos, metodologias, linguagens e processos de } \\
& \text { apropriação. (Projeto Político Pedagógico-do curso, p. 22) }
\end{aligned}
$$

Só na ementa, desta disciplina, verificamos 6 dos 10 indicadores da Rede ACES: compromisso para transformação das relações sociedade-natureza; complexidade; ordem disciplinar (flexibilidade e permeabilidade); considerar o sujeito na construção do conhecimento; orientação de cenários alternativos e adequação metodológica. No decorrer dos 4 anos de curso, é possível identificar indicadores da Rede ACES em 7 das 31 disciplinas que compõem o PPP do curso (quadro 2).

Constatou-se que as disciplinas “Teoria e Prática do Ensino das Ciências Naturais" e "Trabalho e Educação", contemplam os três critérios estabelecidos nas Diretrizes Curriculares Nacionais para identificar a Educação Ambiental na ementa do curso, apresentando transversalidade por meio de temáticas relacionadas ao meio ambiente e a sustentabilidade socioambiental em conteúdos já contemplados no currículo; pela articulação transversal dos componentes Curriculares.

Dispondo-se das categorias, estabelecidas neste trabalho, para identificação de princípios básicos das Políticas Nacionais de Educação Ambiental (PNEA) no PPP do curso de Pedagogia, constatou-se que este PPP não contempla nenhuma das categorias estabelecidas para este item. Embora o ementário de disciplinas do curso contemple os 
conteúdos mínimos definidos pelas Diretrizes Curriculares Nacionais para a Educação Ambiental, o curso não atinge os princípios básicos que foram instituídos nas PNEA.

Quadro 2. Disciplinas obrigatórias que contribuem para a ambientalização curricular, segundo a análise do Projeto Político Pedagógico vigente (2008) do curso de Pedagogia.

\begin{tabular}{|c|c|c|}
\hline DISCIPLINAS AMBIENTALIZADAS & ANO & PRINCIPAL INDICADOR DA REDE ACES \\
\hline História da Educação I & $1^{\mathrm{o}}$ & $\begin{array}{l}\text { Compromisso para a transformação das } \\
\text { relações sociedade-natureza }\end{array}$ \\
\hline Metodologia da pesquisa & $1^{\mathrm{o}}$ & $\begin{array}{l}\text { Considerar o sujeito na construção do } \\
\text { conhecimento }\end{array}$ \\
\hline Psicologia da Educação I & $1^{\mathrm{o}}$ & $\begin{array}{l}\text { Considerar o sujeito na construção do } \\
\text { conhecimento }\end{array}$ \\
\hline $\begin{array}{l}\text { Estágio Supervisionado Sob Forma de } \\
\text { Prática de Ensino I }\end{array}$ & $2^{\circ}$ & $\begin{array}{l}\text { Coerência e reconstrução entre teoria e } \\
\text { prática }\end{array}$ \\
\hline Sociologia da Educação & $2^{\mathrm{o}}$ & $\begin{array}{l}\text { Espaços de reflexão e participação } \\
\text { democrática }\end{array}$ \\
\hline $\begin{array}{l}\text { Teoria e Prática do Ensino das Ciências } \\
\text { Naturais }\end{array}$ & $4^{\circ}$ & $\begin{array}{l}\text { Compromisso para a transformação das } \\
\text { relações sociedade-natureza }\end{array}$ \\
\hline Trabalho e Educação & $4^{\mathrm{o}}$ & $\begin{array}{l}\text { Compromisso para a transformação das } \\
\text { relações sociedade-natureza }\end{array}$ \\
\hline
\end{tabular}

Fonte: Elaborado pelos autores.

Neste plano de análise percebeu-se uma frágil inserção sobre questões ambientais e com a concepção de sustentabilidade em nível das políticas nacionais, constituindo-se em uma lacuna num currículo que objetiva formar cidadãos comprometidos com a transformação social.

\section{Discussão}

Este trabalho teve por objetivo contribuir com a formação dos professores em relação à temática da sustentabilidade. Uma das questões que procuramos demonstrar foi a necessidade da inserção da EA nas instituições de ensino superior. Procurou-se identificar a inserção dos conteúdos de sustentabilidade nas ementas das disciplinas do curso de Pedagogia da Unioeste com o desafio de responder à seguinte questão: "este curso de formação de professores da Unioeste, do campus de Cascavel, está em processo de ambientalização curricular?

Nos estudos de sustentabilidade e da inserção desta temática nas instituições de ensino superior, identificou-se as legislações nacionais que tratam da EA, bem como a Rede ACES, que foi criada com o objetivo de contribuir para as práticas formativas propondo mudanças para os currículos do Ensino Superior. Esta Rede, cujas proposições caminharam para uma formação comprometida com as necessidades de nosso tempo, objetivou instigar que os futuros profissionais atuem em suas atividades, levando-se em conta a necessidade de mudanças em relação aos aspectos ambientais.

Após estes estudos, foi possível definir parâmetros para a análise documental a partir das DCNEA, PNEA e Rede ACES, na qual se estabeleceram categorias para a análise nos ementários de disciplinas do curso, procurando investigar se o mesmo estava em um processo de ambientalização curricular.

Verificou-se, após a análise do ementário de disciplinas, que o curso atende aos parâmetros mínimos estabelecidos pela Rede ACES e pelas DCNEA, porém não contempla os princípios básicos das PNEA. 
Constata-se que os conteúdos escolhidos para formar professores é uma questão problemática, tendo em vista a necessidade de identificar as prioridades de nosso tempo, observando-se que os currículos se constroem em detrimento dos condicionantes históricos, políticos e sociais, os quais firmam uma hierarquia de conhecimentos.

A formação de professores deve ser constantemente questionada, problematizando a validade das prescrições predeterminadas em um mundo em constante transformação com avanços no campo científico e tecnológico que demanda uma formação docente pautada em epistemologias e metodologias da complexidade e da transdisciplinaridade.

O formato disciplinar da organização curricular tem sido evidenciado na literatura da Educação como conhecimentos fragmentados, problematizando o desenho epistemológico dos currículos universitários. Desta forma, estão sendo experimentadas novas organizações interdisciplinares e transdisciplinares em razão da compreensão de que a complexidade e a multiplicidade de relações de conhecimentos revelam que as fronteiras só existem na forma disciplinar.

\section{Conclusão}

Pode-se afirmar que as ementas do curso atendem superficialmente a demanda sustentável da atualidade. Ou seja, o curso, segundo a ementa, e se ela for seguida, está em um processo de ambientalização curricular, porém ainda necessita de atualizações e complementações.

Embora, no perfil profissional deste curso, esteja previsto que o pedagogo será o profissional habilitado para a atividade docente no ensino da educação infantil, nos anos iniciais do ensino fundamental e, ainda, em atividades não docentes que se referem a coordenação pedagógica de uma escola, este futuro profissional não sairá em condições de discutir e ensinar conteúdos relacionados à sustentabilidade.

Esta pesquisa constatou que estão ocorrendo alterações no currículo do curso de Pedagogia da Unioeste. Entretanto, como apontado por Pereira (2008), os currículos continuam sendo reformulados com estrutura disciplinar e com conhecimentos hierarquizados, que não se integram. Considerando-se que o desenvolvimento científico vem se expandindo em todos os campos do conhecimento e se inserindo rapidamente nas atividades cotidianas, é necessário que a temática da sustentabilidade seja integrada nos currículos de forma transversal, em sintonia com as necessidades do nosso tempo histórico.

Diante dos resultados expostos aqui, alguns questionamentos persistem e outros emergem em torno desta temática: As universidades brasileiras vêm atuando de maneira a contemplar o que já está estabelecido nas determinações legais? De que forma os conteúdos de Sustentabilidade estão sendo trabalhados em sala de aula? Como os alunos estão sendo preparados para trabalhar com estes conteúdos na Educação Básica? Considerando-se as determinações do capitalismo do século XXI, os professores podem contribuir como agentes de mudança no atual contexto socioambiental que estamos vivendo? 


\section{Referências}

Bardin, L. (2011). Análise de conteúdo. São Paulo: Edições 70.

Brasil. (1999). Política nacional para educação ambiental. Brasília: Diário Oficial da União.

Brasil. (2006). Diretrizes curriculares nacionais para os cursos de pedagogia. Brasília: Diário Oficial da União.

Brasil. (2012). Diretrizes curriculares nacionais para a educação ambiental. Brasília: Diário Oficial da União.

Boff, L. (2014). Sustentabilidade: o que é-o que não é. Petrópolis: Vozes.

Capra, F. (2006). Alfabetização ecológica: a educação das crianças para um mundo sustentável. São Paulo: Cultrix.

Fernandes, V. (setembro, 2013). Inercia social e educação ambiental. Trabalho apresentado no XI Congresso Nacional de Educação - Educere. Curitiba.

Gore, A. (2006). Uma verdade inconveniente. São Paulo: Manole.

Guerra, A. (setembro, 2013). Ambientalização curricular e sustentabilidade na universidade: concepções de professores e coordenadores de cursos de graduação da UNIVALI. Trabalho apresentado no XI Congresso Nacional de Educação - Educere. Curitiba.

Guimarães, M. (setembro, 2013). A Formação de educadores ambientais em tempo de crise. Trabalho apresentado no XI Congresso Nacional de Educação - Educere. Curitiba.

Junyent, M., Geli, A. e Arbat, E. (2003). Características de la Ambientalización Curricular: Modelo ACES. Girona: Universitat de Girona.

Mészaros, I. (2003). O século XXI: socialismo ou barbárie. São Paulo: Boitempo Editorial.

Moraes, L. (2011). Sistematização de procedimentos do design para a sustentabilidade ambiental para aplicação no ensino de metodologia de projeto. Dissertação de mestrado. Universidade Federal do Rio Grande do Sul, Porto Alegre.

Sachs, I. (2009a). A terceira margem: em busca do ecodesenvolvimento. São Paulo: Companhia das Letras.

Sachs, I. (2009b). Caminhos para o desenvolvimento sustentável. Rio de Janeiro: Garamond.

UNESCO. (2005). Década das nações unidas da educação para o desenvolvimento sustentável (20052014). Brasília: Autor.

Veiga, J. (2010a). Sustentabilidade: a legitimação de um novo valor. São Paulo: Editora Senac São Paulo.

Veiga, J. (2010b). Desenvolvimento sustentável: o desafio do século XXI. Rio de Janeiro: Garamond.

Vilela, R. (2011). Os pressupostos antropocêntricos na crítica ao progresso segundo John Gray. Recuperado de www.marilia.unesp.br/filogenese

Zuin, V. e Freitas, D. (2007). Considerações sobre a ambientalização curricular do ensino superior: o curso de licenciatura em química. Recuperado de http://30reuniao.anped.org.br/posteres/GT222994--Int.pdf

Zuin, V., Farias, C. e Freitas, D. (2009). A ambientalização curricular na formação inicial de professores de Química: considerações sobre uma experiência brasileira. Revista Electrónica de Enseñanza de las Ciencias, 8(2), 552-570. 


\section{Breve CV de los autores}

\section{Talita Rechia Vasconcellos da Rosa}

Possui graduação em Design de Moda pela Universidade Tuiuti do Paraná (2009). Aluna do Programa de Pós-graduação da Universidade Estadual do Oeste do Paraná (UNIOESTE), mestrado em Educação. Atua no Grupo de Pesquisa Formação de Professores de Ciências e Matemática. Aluna do Programa de Pós-graduação em Moda e Gestão no SENAI (PR), finalizando o curso com TCC intitulado Ambientalização curricular nos cursos de Graduação de Design de Moda; Integrante do Grupo de Pesquisa FOPECIM - Formação de Professores de Ensino de Ciências e Matemática, vem desenvolvendo estudos sobre a relação da formação de professores com a Educação Ambiental.Email: tali_rechia@hotmail.com

\section{Vilmar Malacarne}

Possui graduação em Filosofia Licenciatura Plena pela Universidade Federal de Santa Maria (1994), mestrado em Educação pela Universidade Federal de Santa Maria (1997) e doutorado em Educação pela Universidade de São Paulo (2007). Atualmente é professor da Universidade Estadual do Oeste do Paraná. Tem experiência na área de Filosofia e Ensino de Ciências, atuando principalmente nos seguintes temas: Formação de Professores, Ética, Ciência e Religião. Bolsista Produtividade da Fundação Araucária. Email: vilmar.malacarne@unioeste.br 